Vol.1 No.3, Autumn 2020

\title{
The Comparison of Attitude Toward Death and Anxiety Sensitivity between
}

\section{Adolescents with Cancer and Normal Adolescents} \author{
Ahmadi Farsani $\mathrm{M}^{1^{*}}$, Heshmati $\mathrm{R}^{2}$, Hashemi Nosrat Abad $\mathrm{T}^{3}$, Rezazadeh $\mathrm{Sh}^{4}$

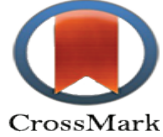 \\ CrossMark \\ 1- MA in Child and Adolescence Clinical Psychology, Department of Psychology, Faculty of Educational Science and \\ Psychology, University of Tabriz, Tabriz, Iran. \\ 2- PhD in Health Psychology, Associate Professor, Department of Psychology, Faculty of Educational Science and Psychology, \\ Tabriz University, Tabriz, Iran. \\ 3- PhD in Educational Psychology, Professor, Department of Psychology, Faculty of Educational Science and Psychology, \\ University of Tabriz, Tabriz, Iran \\ 4- MA Student in Child and Adolescence Clinical Psychology, Department of Psychology, Faculty of Educational Science and \\ Psychology, University of Tabriz, Tabriz, Iran. \\ Corresponding Author: Ahmadi Farsani M, MA in Child and Adolescence Clinical Psychology, Department of Psychology, \\ Faculty of Educational Science and Psychology, University of Tabriz, Tabriz, Iran. \\ Email: Mojtaba.farsani94@gmail.com
}

Received: 20 July 2019

Accepted: 23 August 2019

\begin{abstract}
Introduction: Cancer is the fourth leading cause of death in adolescents. Psychological factors play an important role both in the development and in the sustainability and outcomes of cancer. Among these factors are Attitude to death and Anxiety sensitivity. Therefore, in this research, comparison of Attitude to death and Anxiety sensitivity between adolescents with cancer and normal adolescents are discussed.

Method: For the purpose of this study, from adolescents (15-19 years old) with cancer in the Isfahan province who had come to Health centers and Ala Cancer Prevention and Control Center (MACSA), 60 people were selected by available sampling method, and selected 60 normal adolescent (15-19 years old) of Isfahan High School by Cluster Sampling. Then, the Wong Death Attitude Inventory and Anxiety Sensitivity (AS) Inventory was completed by all two groups. MANOVA was used for the analysis of data.

Results: Result showed that from attitude to death sub scales, Fear of Death, Death Avoidance and Escape Acceptance and also all sub scales of anxiety sensitivity of adolescents with cancer is significantly higher than normal adolescents.

Conclusion: Based on the findings, it can be concluded that attitude to death and anxiety sensitivity play an important role both in the development and in the sustainability and outcomes of cancer in adolescents. So, along with physical interventions, we must take measures to reduce fear of death and death avoidance and anxiety sensitivity in adolescents with cancer.
\end{abstract}

Keywords: Attitude toward death, Anxiety Sensitivity, Cancer.

\begin{tabular}{|l|l|}
\hline \multicolumn{3}{|c|}{ Access this article online } \\
\hline
\end{tabular}




\section{مقايسه نتر ش به مرك و حساسيت اضطر ابى در نوجوانان مبتلابه سر طان و نوجوانان سالم}

مجتبى احمدى فارسانى "'، رسول حشمتى"، تورج هاشمى نصرت آباد"، شهره رضا زاده

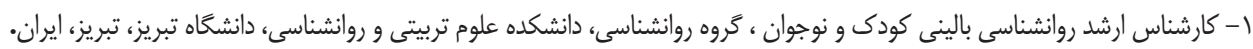

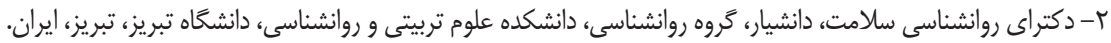

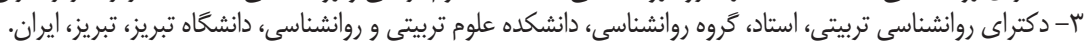

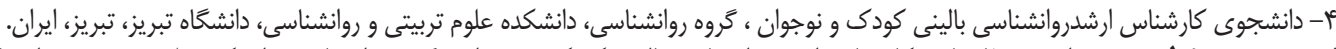

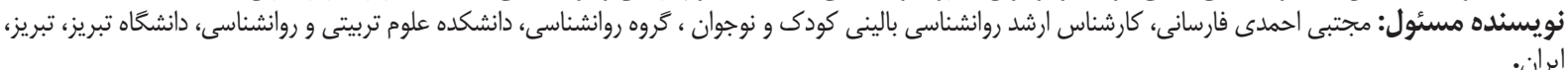

Mojtaba.farsani94@gmail.com ايميل:

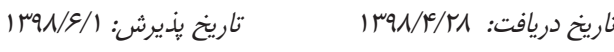

\section{?}

مقدمه: سرطان جِهارمين عامل مركَ و مير در نوجوانان است. عوامل روانشناختى در بيمارى سرطان نقش اساسى دارند. از جمله اين عوامل

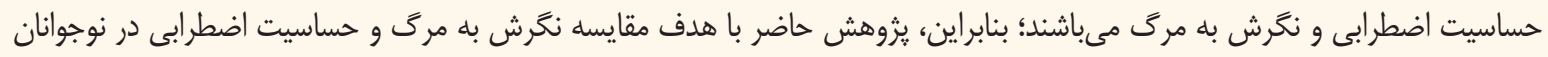
مبتلابه سرطان و عادى صورت كرفت.

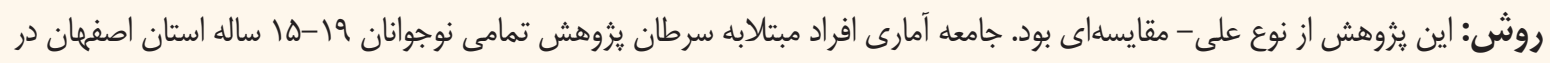

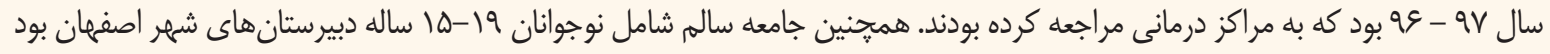

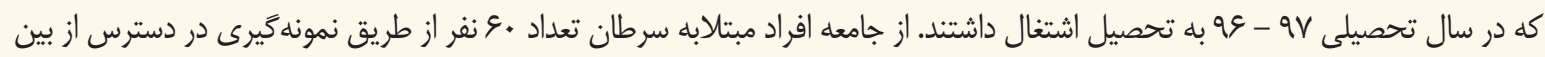

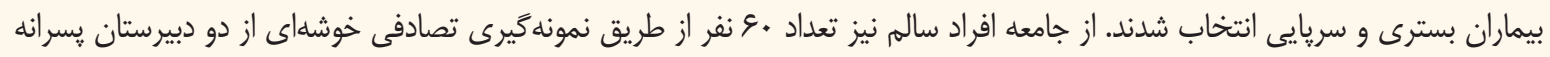

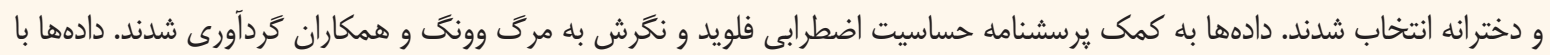

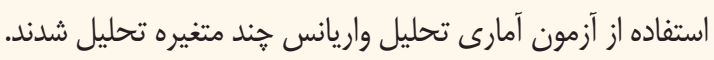

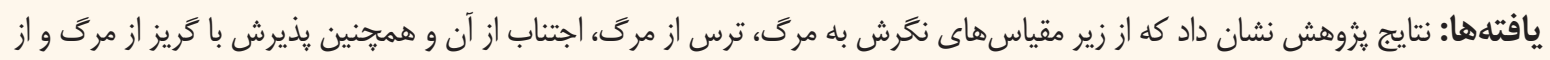

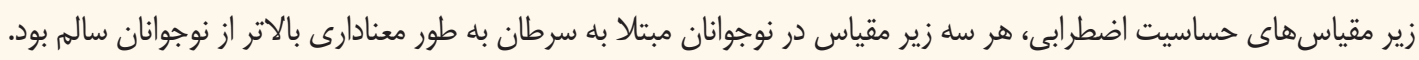

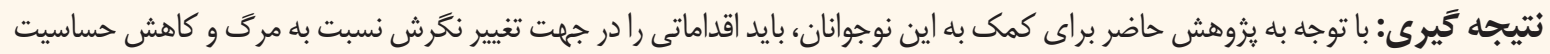
كليدوازه ها: نخرش به مرك، دساسيت اضر ابى، سرطان.

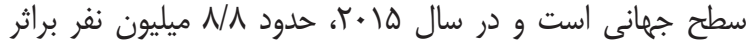
سرطان جان خود را از دست دادهاند. بر اساس كزارش سازمان جهانى

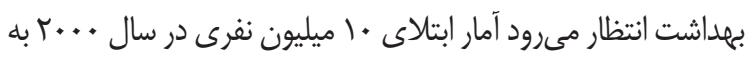

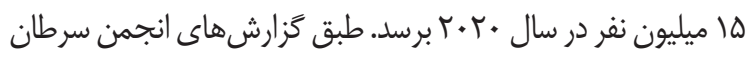

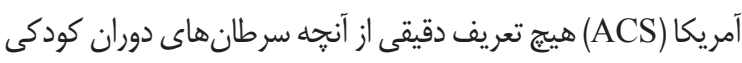

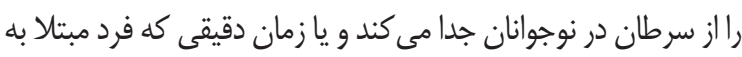
سرطان، يك فرد بالغ در نظر كرفته مى شود، وجود ندارد؛ اما به منظور

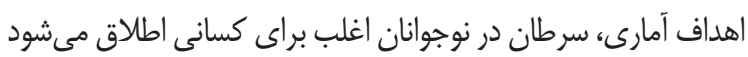
كه بين سنين 10 و 19 دهار سرطان شوند. سرطان در نوجوانان شايع

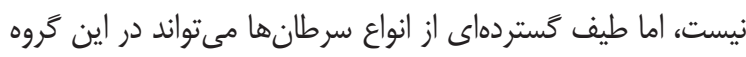

\section{مقلمه4}

در دنياى يِيجيده امروز، انسان با مسائل و مشكلات زيادى روبروست. انسان بايد براى زندكى و بقاء خود با اين مسائل بستيزد و خود را در برد معرض مخاطرات بسيار زياد قرار دهد. از جمله اين مسائل و مشكلات مىتوان به مبتلا شدن به بيمارىهاى مزمن ازجمله سرطان اشاره

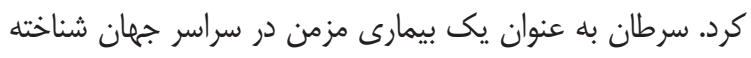

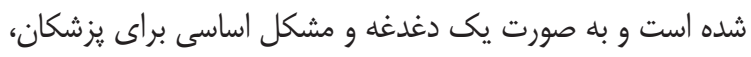

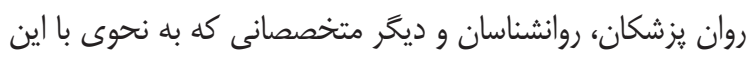

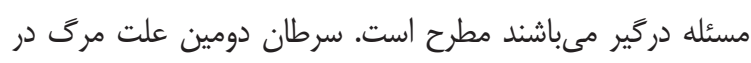


اضطرابى با موقعيتهاى يرتنش مواجه مىشوند (1 ،ج) به طورى كه افر اد با حساسيت اضطر ابى بالا اغلب مواقع به علائم اضطر ابى بلهور منفى واكنش نشان مىدهند، درحالى كه افراد با حساسيت اضطرابى קإيين اثر קه ممكن است علائم را بهعنوان امور ناخوشايند درى

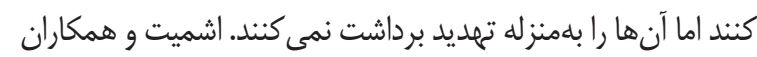

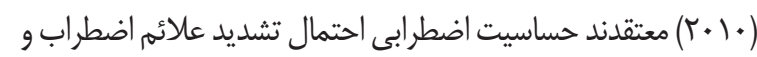

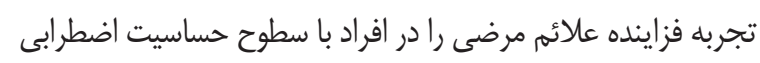

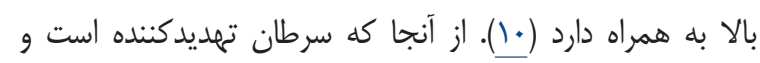

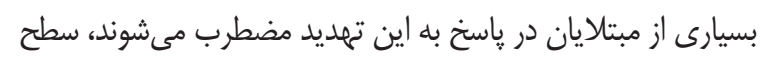
حساسيت اضطر ابى در برخورد با سرطان نقش مهمى دارد. متأسفانه

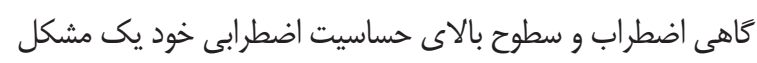

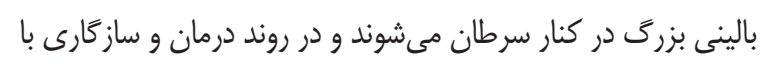
سرطان مشكلات عديدهاى را ايجاد مى كنند.

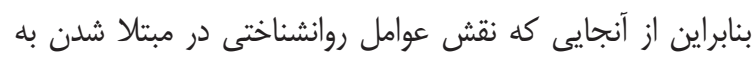

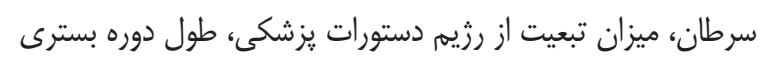

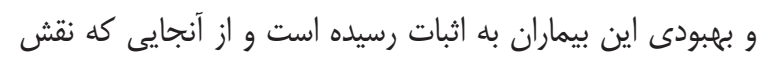

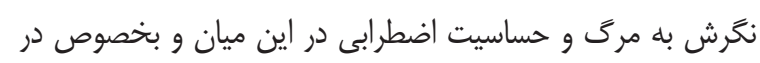

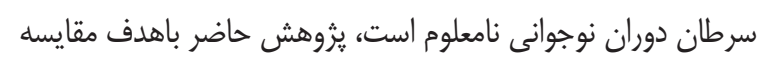

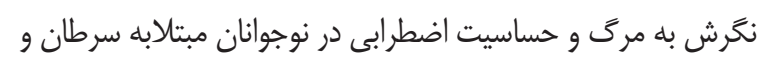

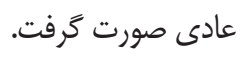

\section{روش مطالعه}

يزوهش حاضر توصيفى تحليلى از نوع على مقايسه اى بود كه مهات

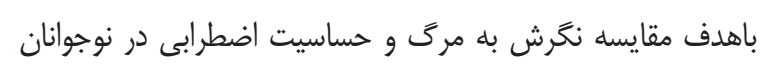
مبتلابه سرطان و عادى صورت كرفت. جامعه آمارى افراد مبتلا به سرطان بروهش تمامى نوجوانان 19-19 ساله استان اصفهان

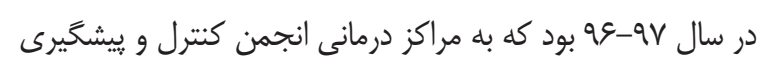
از سرطان آلاء مركز اصفهان و بيمارستان سيدالشهداء اصفهان

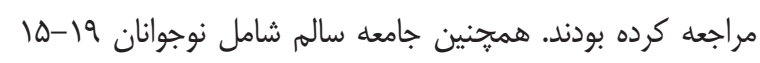

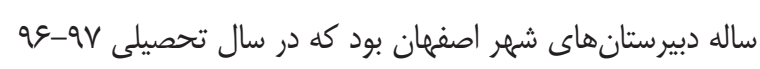

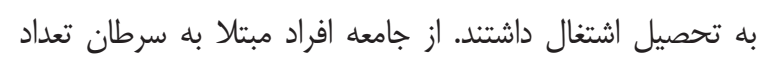
• ع نفر از طريق نمونهَّيرى در دسترس انتخاب شدند. از جامعله

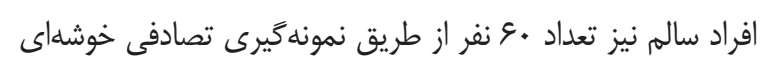

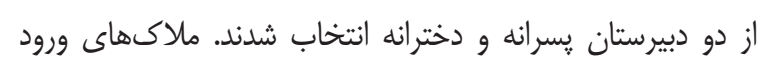

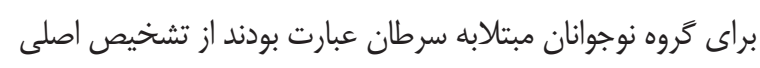

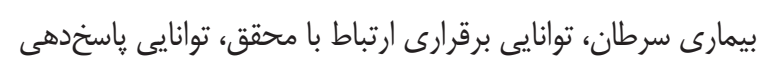

سنى رخ دهد و درمان اين سرطانها بنا به دلايلى مىتواند خالش

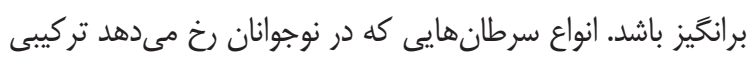

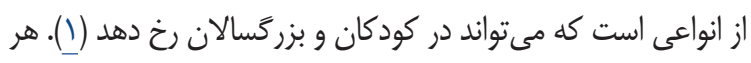
ساله حدود .... نوجوان در سن ها تا 19 سال با علائم سرطان

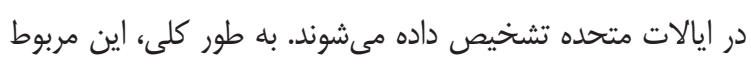

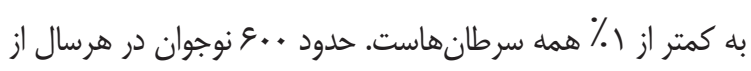

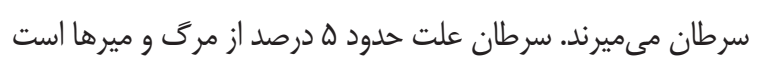
و جهارمين عامل مرك و مير در اين گروه سنى، بعد از تصادفات،

خودكشى و قتل است (1). عوامل روانشناختى در ايجاد سرطان، تداوم و نيز ييامدهاى بيمارى نقش اساسى دارند.. به عنوان مثال تحقيقات نشان دادهاند كه بهان

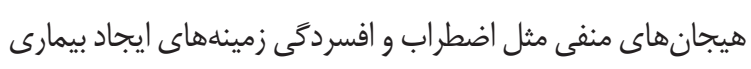

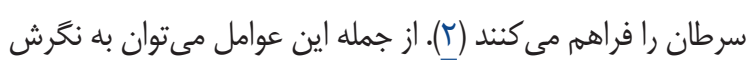
بله مركى و حساسيت اضطرابى اشاره كرد.

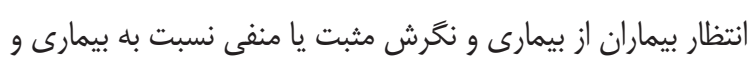

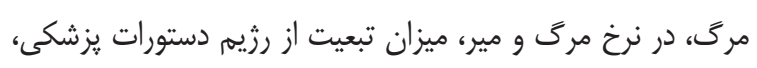

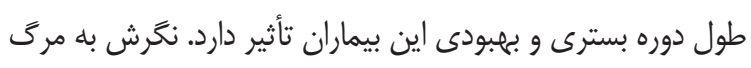

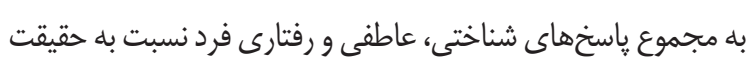

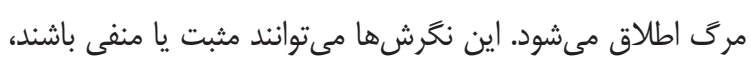

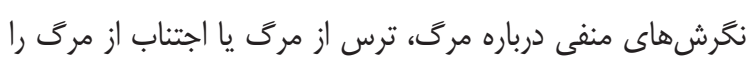

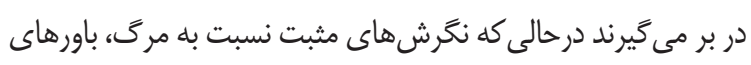

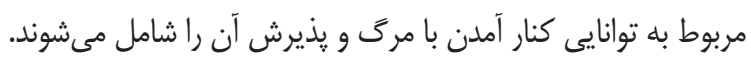

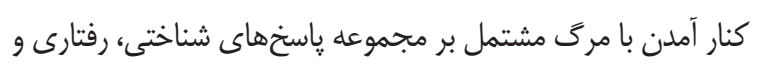

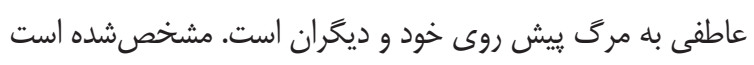

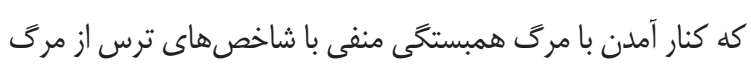
دارد (I) (I). همجنين در اين راستا حساسيت اضطرابى يك سازه شناختى است كه

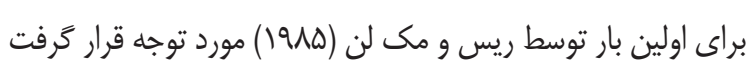
(أ). حساسيت اضطر ابى به لحاظ عملى ترس از اضطراب و احساسات

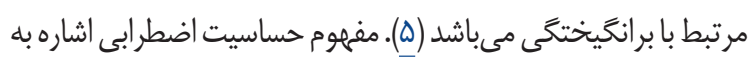

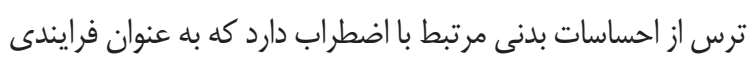

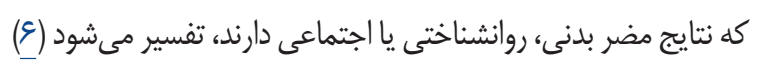

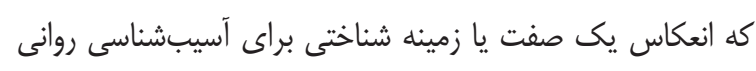

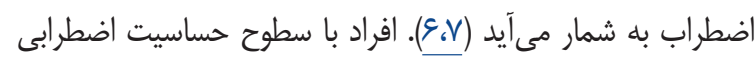

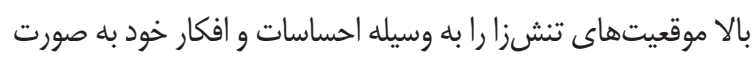

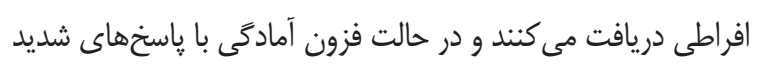




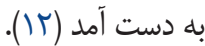
يرسشنامه حساسيت اضطرابى (ASI): اين پرسشنامه توسط فلويد و همكاران ساخته شده است. يرسشنامه حساسيت اضطرابى (ASI) يك يرسشنامه خود گزارش دهى است كه عا گَويه دارد و بر اساس مقياس ينج درجهاى ليكرتى (خيلى كم=ث• تا خيلى زياد=أ) است. هر كَويه اين عقيده را منعكس مى كند كه احساسات اضطرابى بلهورت

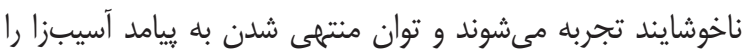
دارند. درجهى تجربهى ترس از نشانههاى اضطرابى با نمرات بالاتر مشخص مىشود. دامنهى نمرات بين • تا عاء است (سا). ساختار اين يرسشنامه از سه عامل ترس از نخرانىهاى بدنى (1 گَويه:

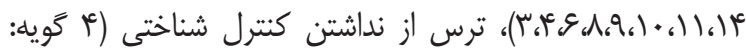

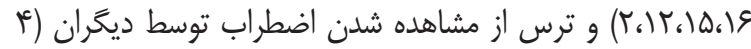

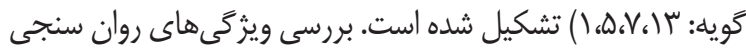
اين مقياس، ثبات درونى آن را (آلفاى بين • ^/ • تا • 9/•) نشان داده

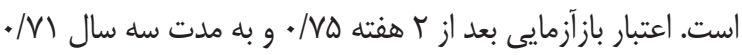

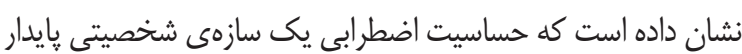
است (1) (1). اعتبار آن در نمونهى ايرانى بر اساس سه روش، همسانى درونى، بازآزمايى و دو نيمه كردن محاسبه شد كه براى كل مقياس

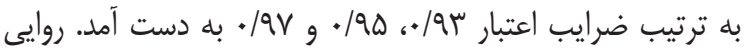
بر اساس سه روش روايى هم زمان، همبستخى خرده مقياسها با مقياس كل و با يكديگر و تحليل عوامل محاسبه شد. روايى هم زمان

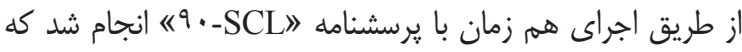
ضريب همبستخى وه/• حاصل آن بود. ضرايب همبستخى با نمره

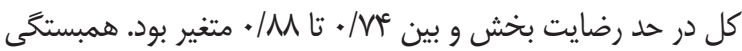

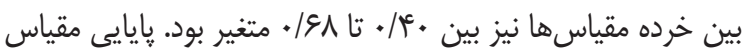
مذكور در يثوهش مشهدى، قاسم يور، اكبرى، ايلبيگى و حسنزاده

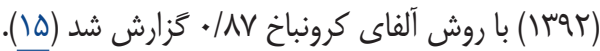

\section{بافتهها}

در اين يزوهش، با توجه به (جدول ()، دو گروه ازلحاظ متغيرهاى جمعيت شناختى مانند جنسيت و وضعيت اجتماعى _ اقتصادى همخَن بودند.
به سؤالهاى يرسشنامهها و تحصيلات حداقل ابتدايى و موافقت و رضايت براى شركت در مطالعه و معيارهاى خروج شامل شرايط طبى عمومى بسيار ضعيف بر اساس نظر يزشك معالج و همجنين عدم تمايل فرد به ادامه همكارى بودند. پِ از انتخاب نمونه و همتاسازى گروهها براى آزمودنىها توضيح داده شد كه جمع آورى دادهها صرفاً جهت يك كار يثوهشى است و اطلاعات محرمانه باقى خواهد ماند، همجنين سوء تفاهمات در مورد متغير نخرش به مرگ نيز برطرف تروفى شد. يّ از اعلام رضايت آزمودنىها، يرسشنامههاى يزوهش در اختيار آنها قرار گرفت كه يس از جمع آورى دادهها، نتايج با استفاده

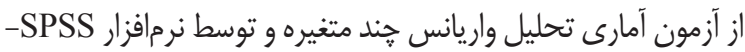

r مورد تحليل قرار گرفت. ابزار يثوهش حاضر عبارت بودند ازي فرم تجديدنظر شده نگرش به مرگ: اين آزمون توسط وونگَ، ييكر و گيسر در سال (1999 ساخته شده است. اين يرسشنامه يك مقياس rس سؤالى است كه ه بعد نگگرش به مرگ شامل ترس از مرگ

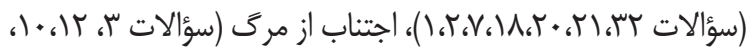

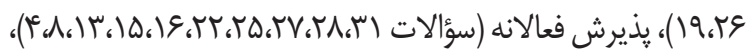

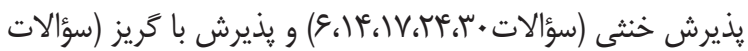

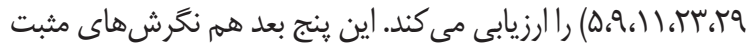
(خرده مقياسهاى يذيرش) و هم منفى (خرده مقياسهاى ترس و اجتناب) نسبت به مرگ را نشان مىدهند. أزمودنى ها پِاسخهاى خود رادر يك مقياس ليكرت V نقطهاى از كاملاً موافقم تا كاملاً مخالفم مشخص مى كنند. نمرات سؤالهاى مربوط به هر خرده مقياس باهم جمع شده و با تقسيم بر تعداد سؤالات ميانگين نمره فرد در آن خرده مقياس به دست مى آيد كه ميانخين بالاتر نشاندهنده يذيرش، ترس و اجتناب بيشتر فرد از مرگ مىباشد (I)). در تحقيقى پايايى ثبات درونى اين ه خرده مقياس را در دامنه QV/• براى خرده مقياس يذيرش فعالانه تا ها\&|• براى خرده مقياس يذيرش خنثى گزارش شد (I)). يايايى باز آزمايى اين آزمون نيز بعد از دوره عا هفتهاى در

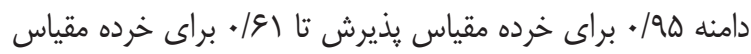
اجتناب به دست آمد (I)!). اين يرسشنامه براى اولين بار در سال

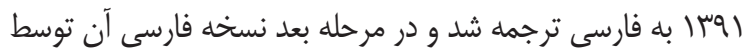
يك كارشناس ارشد زبان انخليسى ترجمه معكوس كَرديد و بعد از اطمينان يافتن از حفظ محتواى سؤالات، ارتباط صورى آن توسط سه روانشناس داراى مدرك دكتراى روانشناسى تائيد شد (با). در اين يثوهش ضريب آلفاى كرونباخ در دامنه ז ع/• براى خرده مقياس اجتناب از مرگ تا M/• براى خرده مقياس يذيرش فعالانه مرگ 
مجتبى احمدى فارسانى و همكاران

جدول (: دادهاى توصيفى مربوط به جنس و وضعيت اجتماعى- اقتصادى به تفكيك كروهها

\begin{tabular}{|c|c|c|c|c|}
\hline فراوانى (درصد) & فوراوانى (درصد) & 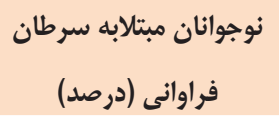 & تَروهها & متغير \\
\hline$\dot{\mu}(F \cdot)$ & $r \Delta(r))$ & $r(19)$ & پֶ, & \\
\hline$V T(\varepsilon \cdot)$ & $r \Delta(r q)$ & $r V(\mu l)$ & دختر & \\
\hline$r \cdot(1 \& / V)$ & $\Delta(F / T)$ & $10(\mid r / \Delta)$ & بإيين & \\
\hline qT (VG/V) & $\operatorname{Qr}(\kappa / V)$ & $F \cdot(\mu \mu)$ & متوسط & -6 \\
\hline$\Lambda(\xi / V)$ & $\Gamma(\Gamma / \xi)$ & $\Delta(F /))$ & بالا & \\
\hline
\end{tabular}

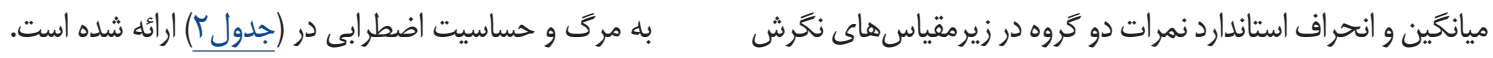

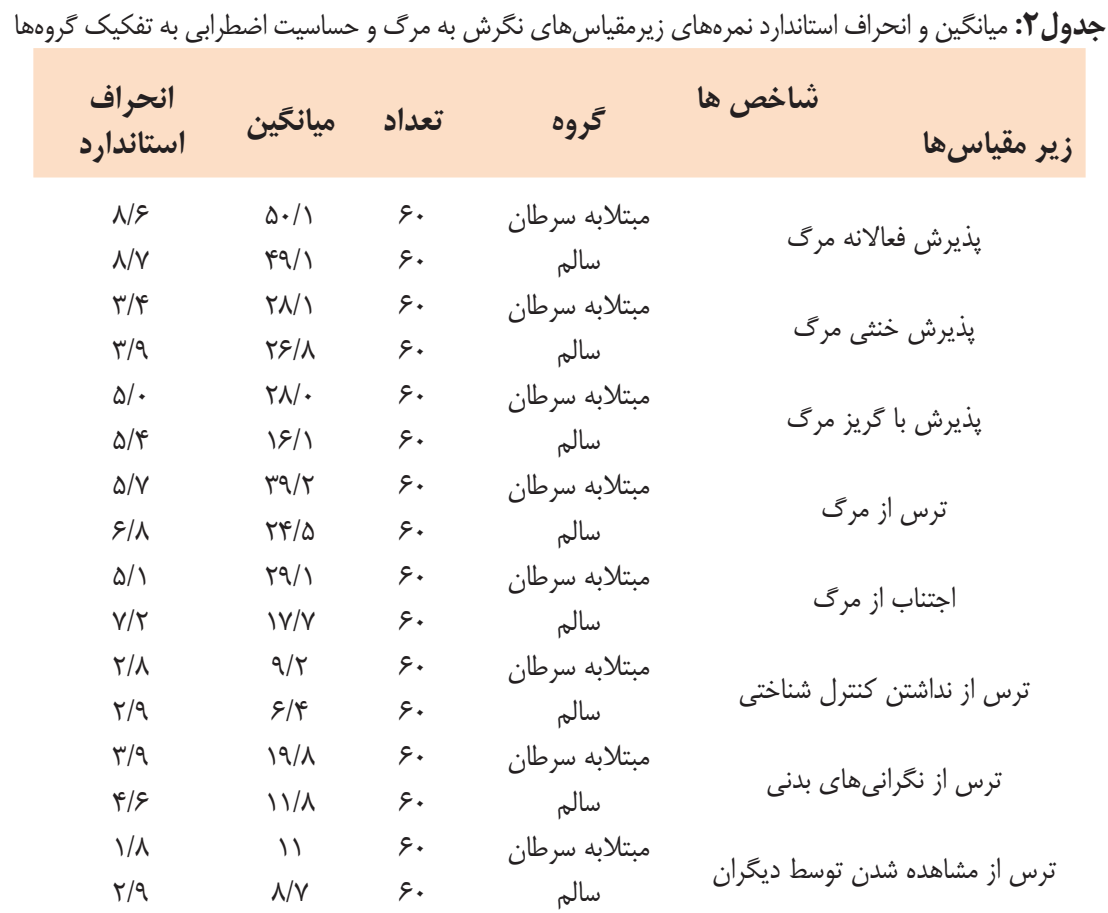

جهت تجزيه و تحليل دادههاى مربوط به تفاوت بين دو كروه آزمون لون و كرويت بارتلت استفاده شد كه با توجه به نتايج اين دو

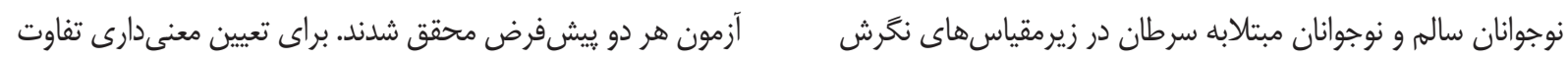

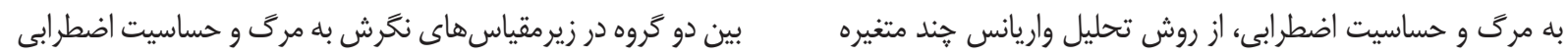

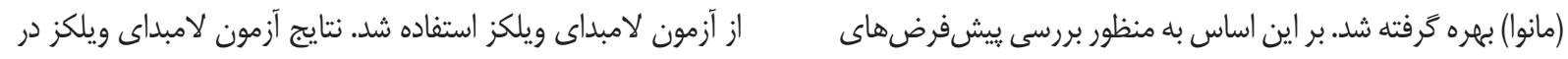

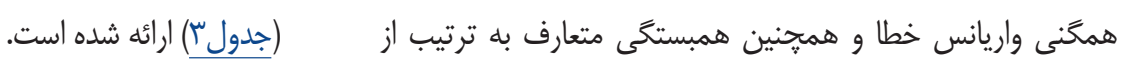
جدول": نتايج آزمون لامبداى ويلكز در تحليل واريانس حند متغيره زيرمقياسهاى نكَرش به مركَ و حساسيت اضطرابى

\begin{tabular}{|c|c|c|c|c|c|c|c|}
\hline توان & $\mathbf{n}^{\Upsilon}$ & سطح معنىدارى & $\mathbf{F}$ & درجه آزادى خطا & درجه آزادى & اندازه & آزمون \\
\hline 1 & ./va & $\cdot|\cdots|$ & $\Delta F / V$ & 111 & $\wedge$ &.$/ \pi$. & لامبداي ويلكز \\
\hline
\end{tabular}

وجود دارد. براى بررسى اينكه كدام زير مقياسها باعث اين تفاوت

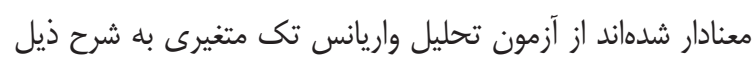

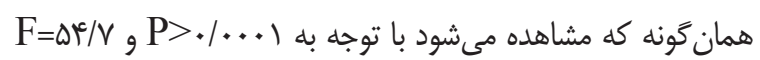

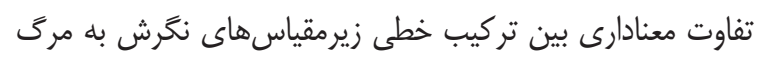

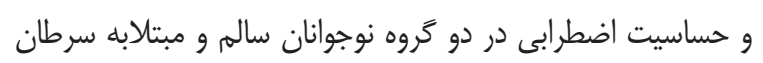


جدول أ: نتايج تحليل واريانس تك متغيرى در زيرمقياسهاى نگرش به مرگ و حساسيت اضطرابى با توجه به كروه

\begin{tabular}{|c|c|c|c|c|c|c|c|c|}
\hline توان & $\mathbf{n}^{r}$ & معنى دارى & $\mathbf{F}$ & مجذانگَين & آزادى درجه & مجذورات & متغير وابسته & تغيير \\
\hline$\cdot 1$ & $\%+\cdot \varphi^{c}$ & $\cdot / 199$ & $\cdot / \kappa^{c}$ & $r \Delta / 1$ & 1 & r山/ & يذيرش فعالانه مرى & \multirow{8}{*}{ 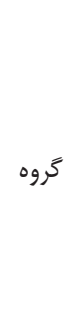 } \\
\hline$\cdot / 4 V$ &.$\mu$ & 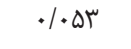 & $r / \varepsilon$ & FN/I & 1 & $\uparrow N / 1$ & يذيرش خنثى مرى & \\
\hline 1 & $\cdot / \Delta \varphi$ & $\cdot 1 \cdot \cdots \cdot 1$ & $1 \Delta \omega / \Gamma$ & FTAF/S & 1 & FTAF/\& & يذيرش با گريز مرى & \\
\hline 1 & $\cdot / \Delta \Lambda$ & $.1+\cdots 1$ & $\mid q \pi / \kappa^{c}$ & $9 \times 99 / 4$ & 1 & $9 \times 99 / \%$ & ترس از مرك & \\
\hline 1 & $\cdot / \& \Delta$ & $.1+\cdots 1$ & $99 / 8$ & rquk/g & 1 & rqu/lq & اجتناب از مرگ & \\
\hline 1 & . & $\cdot 1+\cdots 1$ & $r q / 4$ & $M F \cdot / \varepsilon$ & 1 & $M Y \cdot / \varepsilon$ & ترس از نداشتن كنترل شناختى & \\
\hline 1 & $\cdot / 4$ & $\cdot 1 \cdot \cdots 1$ & $1 \cdot r / 1$ & $191 \% / \pi$ & 1 & $191 \% / r$ & ترس از نخرانى هاى بدنى & \\
\hline 1 & $\cdot / 1 \Lambda$ & $\cdot 1+\cdots 1$ & $r \varepsilon / \varepsilon$ & $\mid Q V / S$ & 1 & $\mid Q V / \&$ & ترس از مشاهده شدن توسط ديخران & \\
\hline
\end{tabular}

نشده است) با تشخيص سرطان مواجه شود شوكه مىشود و عاقبت سرطان يعنى مرگ را در جلوى خود مىييند، اين امر غيرمنتظره

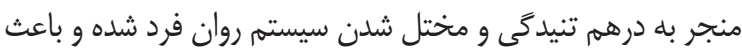

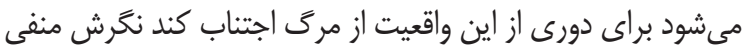
نسبت به مرگ داشته باشد.

همجنين مىتوان اين يافته را اين گُنه تبيين كرد كه در مقايسه باس

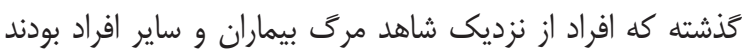
و در نتيجه مرگ براى آنها ملموس تر بود، در جامعه مدرن با نوعى سر كوب شدن مرگ و نوعى وايس زنندگى نسبت به آن مواجه

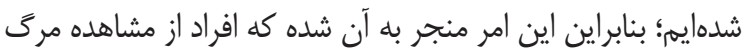

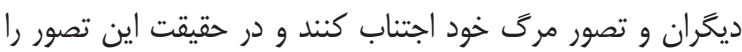
به ناهشيارى مىفرستند. همانطور كه كيه (9 . + r) نيز كَته زمانى كه فرد مبتلابه سرطان تشخيص داده مىشود بهطور هولناكى با اين

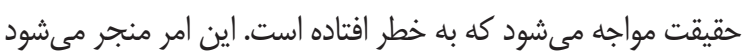
كه افكار سركوب شده و ناهشيار مرگ به هشيارى راه بيدا كنند و به شكل ترس، اضطراب و يا اجتناب از مرگ نشان داده شوند (Tr). يافته ديخرى كه اين يزوهش داشت اين بود كه نوجوانان مبتلابه

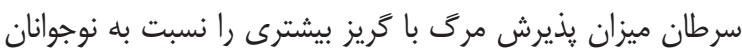
عادى داشتند. اين يافته با يزوهش بريت بارت و همكاران كه روى r9 بيمار مبتلابه سرطان بسترى در بيمارستان انجام دادند و به

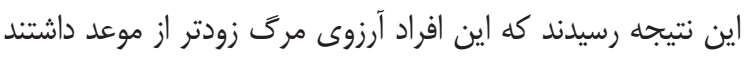

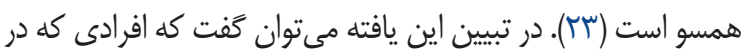
زندگىشان از دردها رنجهاى مزمنى همجون بيمارى سرطان، رنج مىبرند با شكل دادن اين باور كه مرگ راهى براى پايان دادن به اين مشكلات است مرگ را مىيذيرند و با آن كنار مى آيند.

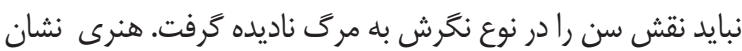
داد كه سالمندان و ميانسالان نسبت به افراد جوانتر از معنويت و اعتقادات مذهبى بيشتر و اضطراب مرى كمترى برخوردار هستند

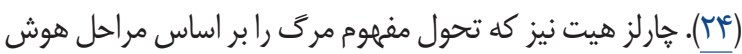

همان گَنه كه مشاهده مىشود، بين دو ₹روه نوجوانان مبتلابه سرطان

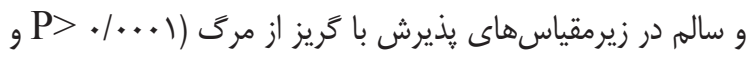
س/

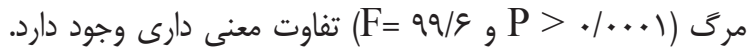
همجنين هر سه زير مقياس حساسيت اضطرابى در نوجوانان مبتلا

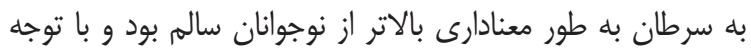

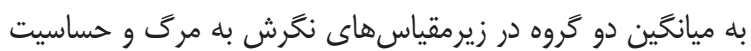
اضطرابى در (جدول r)، مشخص مىشود كه گروه نوجوانان مبتلا به ميه سرطان در زير مقياس ذكر شده نمرات بالاترى را به خود اختصاص

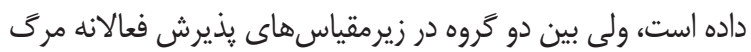
و يذيرش خنثى مرى تفاوت معنادارى مشاهده نشد.

\section{بحث و نتيجه تيرى}

نتايج اين مطالعه نشان داد كه نوجوانان مبتلابه سرطان نسبت به نوجوانان عادى نخرش منفىترى نسبت به مرگ دارند يا به عبارتى ميزان ترس از مرگ و همجنين اجتناب از مرگ در نوجوانان مبتلابه

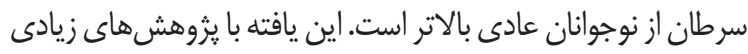

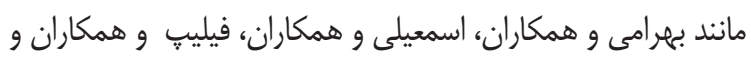
كورتولان، همسو است (19-19). مطالعه گيبسون و همكاران نشان داد كه كودكان و افراد جوان مبتلابه سرطان، در اوايل تشخيص ابتلا به سرطان از مردن ترسيده بودند (•r). در مطالعه انجام شده توسط ميسل و بريكلند بيان داشتند كه تشخيص سرطان باعث ياس و ورسيداه ناميدى بيمار شده و آنها احساس مى كنند كه در يك موقعيت غيرقابل كنترل و سخت گير كردهاند (آr). احساسى كه اين افراد ״س از مواجه شدن با مرگ دارند، حس مرگ قريبالوقوع و نزديك

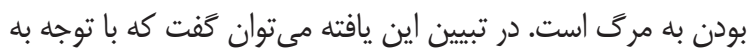
بالا بودن ميزان مرگَومير ناشى از سرطان و ديد منفى گَسترداى كه بلهبع آن نسبت به عاقبت سرطان ايجاد شده، زمانى كه فرد و بخصوص نوجوان (كه هنوز از نظر روانى براى مواجه با مرى آماده 
مدت فرد با يك بيمارى مزمن، داراى منشأ جسمانى و خطرناك فرد

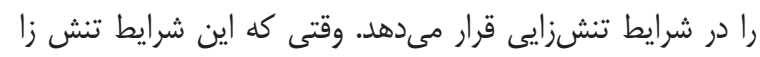

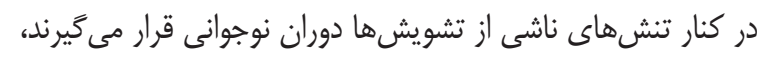

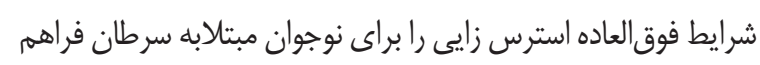

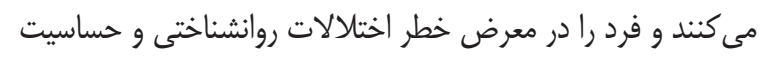

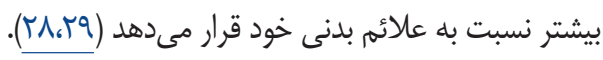

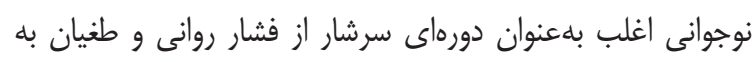

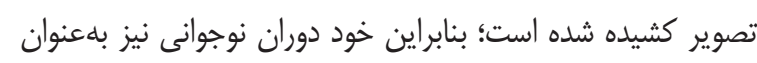

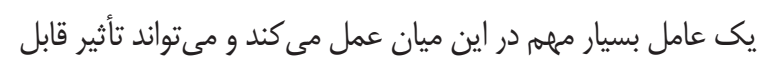

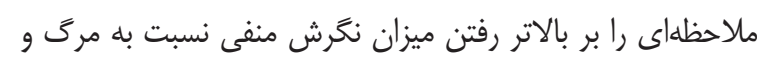
همجنين حساسيت اضطر ابى بكذارد.

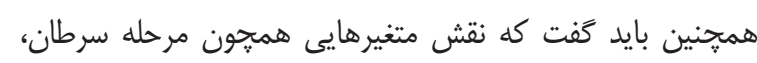

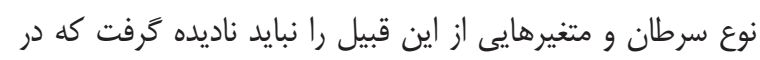

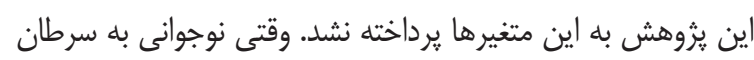

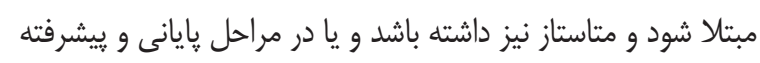
سرطان نظير مرحله IV و III قرار داشته باشد، مسلماً و به احتمال فراوان نسبت به بيمارانى كه در مراحل اوليه و تشخيص ابتدايى

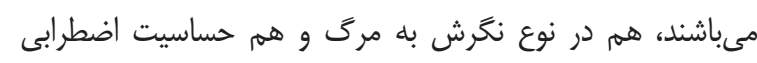

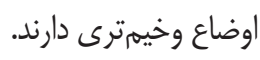
نتايج اين مطالعه نشان داد كه نوجوانان مبتلا به سرطان نسبت بان بهن

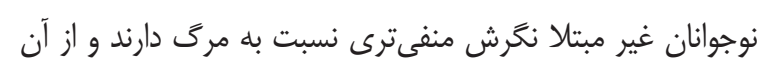

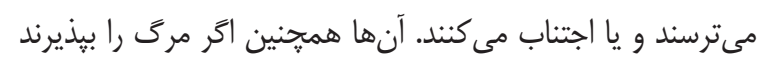

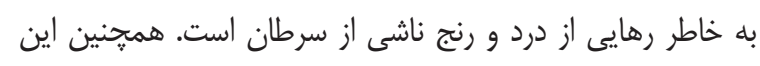

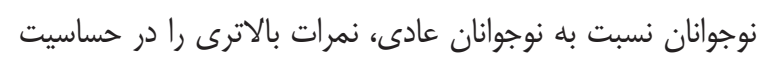

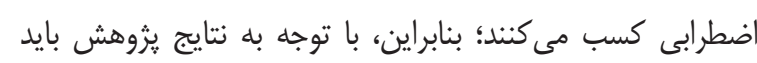

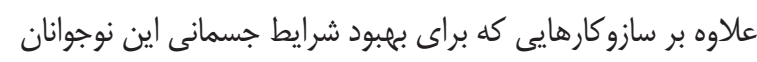

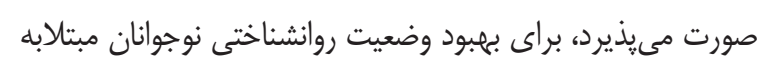

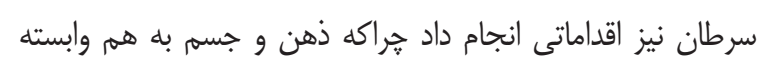

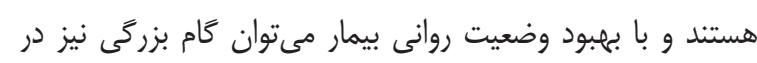

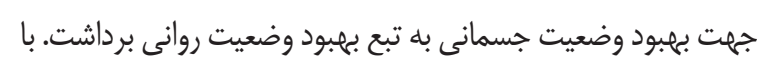

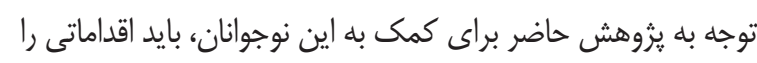

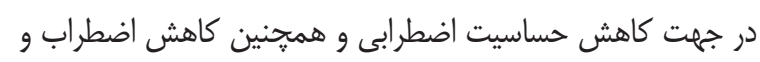
ترس از مرى و همجنين عدم اجتناب از آن انجام داديت

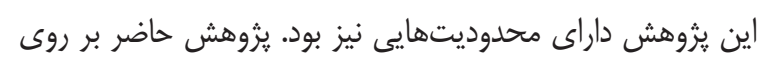

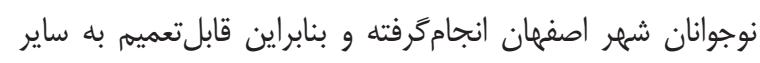

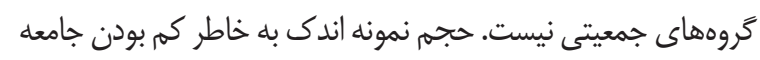

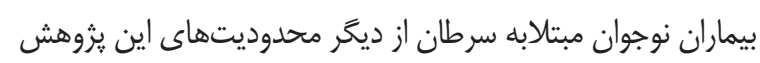

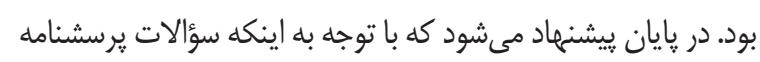

تقسيهبندى كرده است، معتقد است كه افراد در جريان تحول روانى نكَرشهاى متفاوتى نسبت به مرك و فقدان دارند. اين تفاوتها

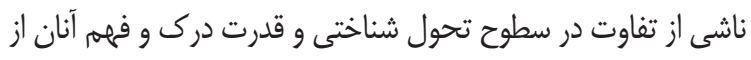

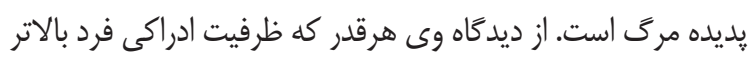

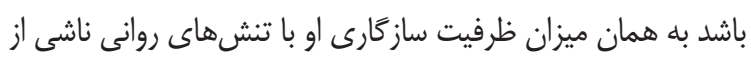

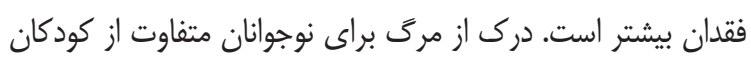

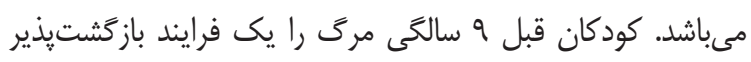

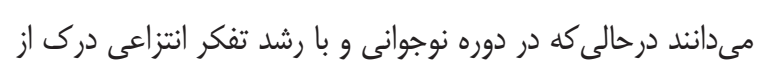

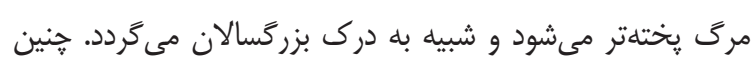

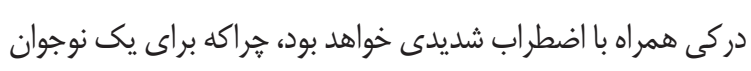

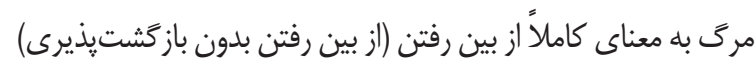
يافتههاى يزوهش حاضر همجنين نشان داد، ميزان حساسيت

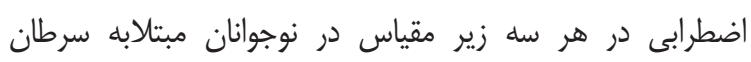

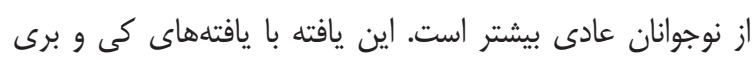

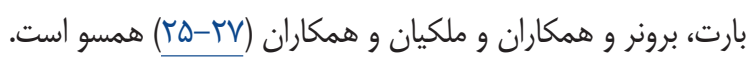

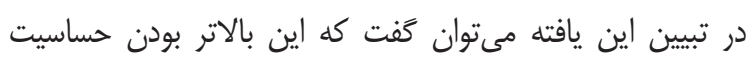

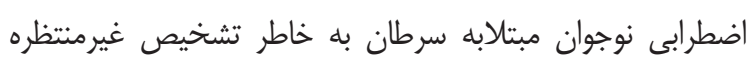

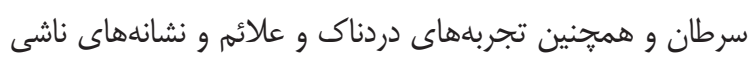

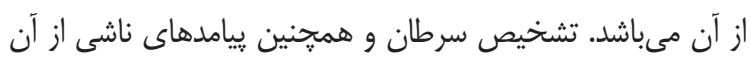
يعنى علائم و نشانهالى شناختى و جسمانى، باعث تحريك سيسته

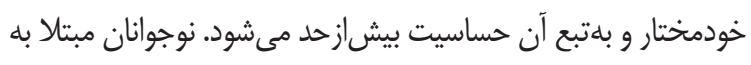
سرطان اين عوامل را خطرزاو همجينين تهديد كننده حيات مى يندارد

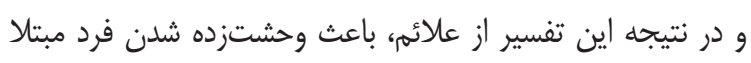
مى شود كه در نهايت اين بيماران را مستعد اضطراب و و حساسيت

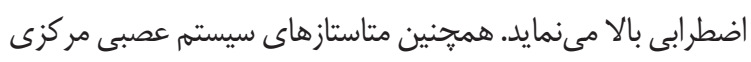

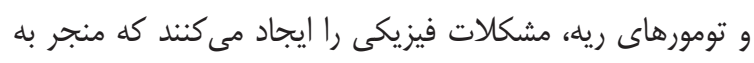

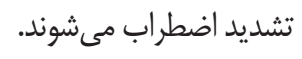

همجنين احتمال ديكرى كه وجود دارد اين است كه مشكلات

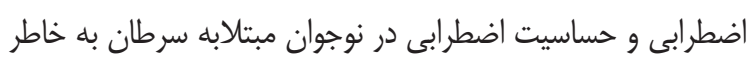

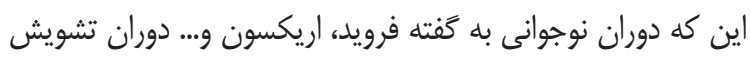

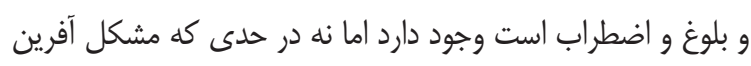
باشند. زمانى كه شخص با تشخيص سرطان و علائم و يبامدهاى

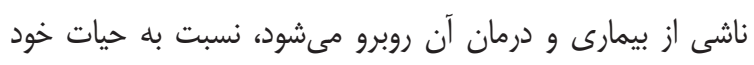

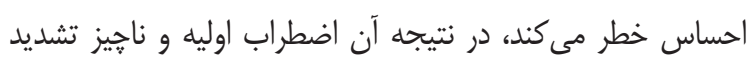
مىشود و خود را به صورت مشكلات اضطرابى و ازجمله در نيجه ان حساسيت اضطر ابى بالا نشان مى دهد. همجنين در تبيين اين يافته مىتوان كفت كه دركير بودن طولانى 


$$
\begin{aligned}
& \text { اين تحقيق با همكارى مركز كنترل و ييشخَيرى از سرطان آلاء مركز } \\
& \text { اصفهان و بيمارستان سيدالشهماء (اميد) اصفهان صورت گرفت. بدين } \\
& \text { وسيله از همه عزيزانى كه ما را در اجراى اين طرح يارى رساندند، } \\
& \text { نهايت تشكر و قدردانى را به عمل مى آوريه. }
\end{aligned}
$$

\section{References}

1. Available from: https://www.cancer.org/content/ dam/cancer-org/research/cancer-facts-andstatistics/annual-cancer-facts-and-figures/2014/ special-section-cancer-in-children-and adolescents-cancer-facts-and-figures-2014.pdf

2. Pitman A, Suleman S, Hyde N, Hodgkiss A. Depression and anxiety in patients with cancer. Bmj. 2018 Apr 25; 361: k1415.

3. Robbins RA. Bugen's Coping with Death Scale: Reliability and further validation. OmegaJournal of Death and Dying. 1991 Jun; 22 (4): 287 - 99.

4. Mantar A, Yemez B, Alkın T. Anksiyete duyarlılığ1 ve psikiyatrik bozukluklardaki yeri. Turk Psikiyatri Derg. 2011 Sep 1; 22:187 - 93.

5. McNally RJ. Anxiety sensitivity and panic disorder. Biological psychiatry. 2002 Nov 15; 52 (10): 938 - 46.

6. Taylor S. Anxiety sensitivity: Theory, research, and treatment of the fear of anxiety. Routledge; 2014 May 12 ..

7. Bernstein A, Zvolensky MJ, Vujanovic AA, Moos R. Integrating anxiety sensitivity, distress tolerance, and discomfort intolerance: A hierarchical model of affect sensitivity and tolerance. Behavior Therapy. 2009 Sep 1; 40 (3): 291-301.

8. Rapee RM, Medoro L. Fear of physical sensations and trait anxiety as mediators of the response to hyperventilation in nonclinical subjects. Journal of Abnormal Psychology. 1994 Nov; 103 (4): 693.

9. Marshall GN, Miles JN, Stewart SH. Anxiety sensitivity and PTSD symptom severity are reciprocally related: Evidence from a longitudinal study of physical trauma survivors. Journal of abnormal psychology. 2010 Feb; 119 (1): 143.

10. Schmidt NB, Keough ME, Mitchell MA, Reynolds EK, MacPherson L, Zvolensky MJ,

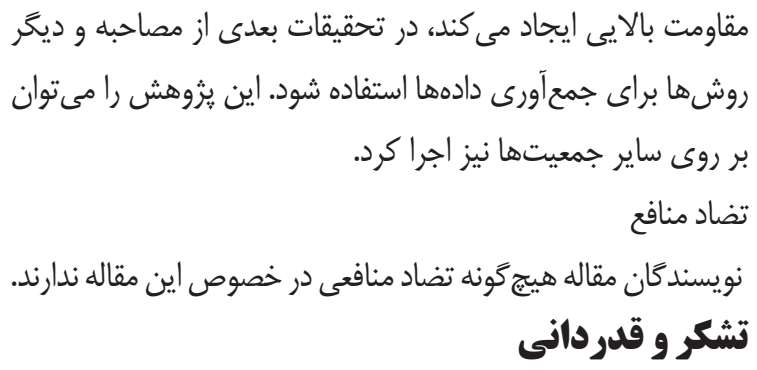

Lejuez CW. Anxiety sensitivity: Prospective prediction of anxiety among early adolescents. Journal of anxiety disorders. 2010 Jun 1; 24 (5): 503 - 8 .

11. Wong PT, Reker GT, Gesser G. Death Attitude Profile-Revised: A multidimensional measure of attitudes toward death. Death anxiety handbook: Research, instrumentation, and application. 1994; 121.

12. Basharpoor S, Vojoodi B, Atarod N. Relationship between religious orientation and attitude toward death with quality of life and signs of physicalization in women. Health Psychology. 2011; 3 (10): 80-97 (Persian).

13. Floyd M, Garfield A, LaSota MT. Anxiety sensitivity and worry. Personality and Individual Differences. 2005 Apr 1;38 (5):1223 - 9.

14. Reiss S, Peterson RA, Gursky DM, McNally RJ. Anxiety sensitivity, anxiety frequency and the prediction of fearfulness. Behaviour research and therapy. 1986 Jan 1; 24 (1): 1-8.

15. Mashhadi A, Gasempoor A, Akbari E, ElBeigi R, Hasanzadeh SH. The Role of Anxiety Sensitivity and Emotion Regulation in Prediction of Social Anxiety Disorder in Students. Knowledge \& Research in Applied Psychology. 2013; 14 (2): 90 - 100 (Persian).

16. Bahrami N, Moradi M, Soleimani MA, Kalantari Z, Hosseini F. Death anxiety and its relationship with quality of life in women with cancer. Iran Journal of Nursing. 2013 Jun; 26 (82): 51-61.

17. Esmaeili R, Ahmadi F, Mohammadi E, Tirgari Seraj A. Life Threatening: The Most Important Concern of Patients Confronting Cancer Diagnosis. Hayat. 2013; 18 (5):12-22 (Persian).

18. Philipp R, Mehnert A, Lo C, Müller V, Reck M, Vehling S. Characterizing death acceptance among patients with cancer. Psycho-oncology. 2019 Apr; 28 (4): 854 - $62 .$.

19. Kurtulan MH, Karairmak Ö. Examination of the 


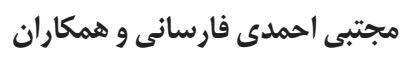

Relationship among Death Anxiety, Spirituality, Religious Orientation and Existential Anxiety. Spiritual Psychology and Counseling. 2016; 1 (2): $206-217$.

20. Gibson F, Aldiss S, Horstman M, Kumpunen S, Richardson A. Children and young people's experiences of cancer care: a qualitative research study using participatory methods. International journal of nursing studies. 2010 Nov 1; 47 (11):1397 - 407.

21. Missel M, Birkelund R. Living with incurable oesophageal cancer. A phenomenological hermeneutical interpretation of patient stories. European Journal of Oncology Nursing. 2011 Sep 1; 15 (4): 296 - 301.

22. Karimi, M. Sociology of Death. East newspaper.2006: 777:18.

23. Breitbart W, Rosenfeld B, Pessin H, Kaim M, Funesti-Esch J, Galietta M, Nelson CJ, Brescia R. Depression, hopelessness, and desire for hastened death in terminally ill patients with cancer. Jama. 2000 Dec 13; 284 (22):2907-11.

24. Henrie JA. Religiousness, future time perspective, and death anxiety among adults. West Virginia University; 2010.

25. Key RG, Breitbart WS. Mood and Anxiety in Cancer Pain. InEssentials of Interventional Cancer Pain Management 2019 (pp. 473-483). Springer, Cham.

26. Bronner MB, Nguyen MH, Smets EMA, van de Ven AWH, van Weert JCM. Anxiety during cancer diagnosis: examining the influence of monitoring coping style and treatment plan. Psychooncology. 2018: 27 (2): 661 - 667. doi:10.1002 /pon.4560.

27. Malekian A, Alizadeh A, Ahmadzadeh GH. Anxiety and Depression in Cancer Patients. J Res Behavior Sci. 2007; 5: 115-118.

28. García-Campayo, J., Rosel, F., Serrano, P., Santed, M.A., Andrés, E., Roca, M., Serrano-Blanco, A., \& Latre, M.L. Different psychological profiles in non-cardiac chest pain and coronary artery disease: a controlled study. Revista espanola de cardiologia. 2010: 63 (3): 357-61.

29. Sheehan A. Non-cardiac chest pain: the role of physical, psychosocial, and service-related factors in the persistence of pain and health service use. 